\title{
Blood meal sources and entomological inoculation rates of anophelines along a highland altitudinal transect in south-central Ethiopia
}

\author{
Abebe Animut ${ }^{1,2^{*}}$, Meshesha Balkew², Teshome Gebre-Michael ${ }^{2}$ and Bernt Lindtjørn ${ }^{1}$
}

\begin{abstract}
Background: The role of anophelines in transmitting malaria depends on their distribution, preference to feed on humans and also their susceptibility to Plasmodium gametocytes, all of which are affected by local environmental conditions. Blood meal source and entomological inoculation rate of anophelines was assessed along a highland altitudinal transect in south- central Ethiopia.
\end{abstract}

Methods: Monthly adult anopheline sampling was undertaken from July 2008 to June 2010 in Hobe (low altitude), Dirama (mid altitude) and Wurib (high altitude) villages located at average elevations of $1800 \mathrm{~m}, 2000 \mathrm{~m}$ and 2200 m, respectively. Anophelines were collected using CDC light trap, pyrethrum space spray catches (PSC) and artificial pit shelter methods. Upon collection, females were categorized according to their abdominal status and identified to species. Their human blood index, sporozoite rate and entomological inoculation rate was determined.

Results: A total of 4,558 female anophelines of which Anopheles arabiensis was the most prevalent (53.3\%) followed by Anopheles demeilloni (26.3\%), Anopheles christyi (8.9\%), Anopheles pharoensis (7.9\%) and Anopheles cinereus (3.6\%) were caught and tested for blood meal source or sporozoite infection depending on their abdominal status. The proportions of human fed and bovine fed An. arabiensis were generally similar. In the low altitude village, there were $0.3 \%(1 / 300)$ and $0.2 \%$ (1/416) Plasmodium falciparum infected An. arabiensis among the CDC trap catches and PSC respectively. The percentage of Plasmodium vivax infected An. arabiensis were 3\% (9/300) and 0.7(3/416) among the CDC and PSCs respectively in the village. In addition, there were 1.4\% (1/71) and 50\% (1/2) P. vivax infected An. pharoensis from the CDC light trap and PSCs, respectively. In the mid altitude village, 2.5\% (1/40) and $1.7 \%(1 / 58)$ from among the CDC and PSCs of An. arabiensis respectively carried $P$. vivax sporozoites. Among the CDC light trap catches; there were 3.7 and 0 P. falciparum infective bites per year per household for An. arabiensis in the years July 2008 to June 2009 and July 2009 to June 2010 respectively in the low altitude village. The corresponding numbers for P. vivax infective bites for An. arabiensis were 33 and 14.5 in the same village. Space spray catches revealed $0.32 \mathrm{P}$. vivax infective bites per household for An. pharoensis during the first year in the low altitude village.

Conclusion: Anopheles arabiensis was the most prevalent vector of $P$. vivax and $P$. falciparum malaria in the low and mid altitude villages followed by An. pharoensis. Annual entomological inoculation rates showed that vivax malaria transmission was higher than that of the falciparum and both decreased with increase in altitude.

\footnotetext{
* Correspondence: animut2004@yahoo.com

${ }^{1}$ Center for International Health, University of Bergen, Bergen, Norway

${ }^{2}$ Aklilu Lemma Institute of Pathobiology, Addis Ababa University, P. O. Box

1176, Piazza, Ethiopia
}

\section{Biomed Central}

(c) 2013 Animut et al.; licensee BioMed Central Ltd. This is an Open Access article distributed under the terms of the Creative Commons Attribution License (http://creativecommons.org/licenses/by/2.0), which permits unrestricted use, distribution, and reproduction in any medium, provided the original work is properly cited. 


\section{Background}

Plasmodium falciparum and Plasmodium vivax are the most prevalent malaria parasites in Ethiopia [1] of which the first is the most notable cause of sickness and death. Transmission of the disease is unstable and occurs mainly from September to December following the June-September rains while the minor transmission occurs in April to May following the February-March small rains. Areas between 1,500 $\mathrm{m}$ and 2,500 $\mathrm{m}$ altitude have been affected by epidemics at intervals of 5-8 years while those below 1, $500 \mathrm{~m}$ are affected by seasonal transmission. Moreover, the increasing magnitude of the global temperature and ecological changes [2-5] might have contributed in the expansion of the disease to areas higher than 2, $500 \mathrm{~m}$ altitude [6-8].

Anopheles arabiensis is the principal malaria vector in Ethiopia [9] while Anopheles pharoensis, Anopheles funestus and Anopheles nili are secondary vectors [1,10,11]. Anopheles arabiensis is adapted to diverse ecology, feeding preference, seasonal occurrence and vectorial capacity resulting in diverse spatial and temporal malaria transmission patterns [12-14]. The role of anophelines in transmitting the disease depends on their occurrence and preference to feed on humans [15], which in turn is affected by local socio-economic as well as environmental factors $[14,16]$. Thus, preventing humans from the bite of vectors can reduce malaria transmission. However, implementation of prevention tools requires knowledge on occurrence, feeding behaviour and entomological inoculation rate of the vector in the local setting $[17,18]$.

Preference of anophelines to feed on humans can be estimated using human blood index (HBI). HBI is the proportion of human fed among a total of fresh fed anophelines. However, as a vector may feed on alternative hosts depending on availability and accessibility, it remains imperative to assess its blood meal source in local settings. Tests such as enzyme-linked immunosorbent assay (ELISA) [19,20], precipitin test [10] and polymerase chain reaction (PCR) [16] can be employed to identify the blood meal source of a vector of which the first is preferable.

Risk of malaria infection can be measured using entomological inoculation rate (EIR) [20,21]. EIR of a vector depends on its human biting frequency and susceptibility to Plasmodium gametocytes $[15,22]$. It is the product of the human biting rate (HBR) and the sporozoite rate (SR) [17]. The human bait catch is considered as the gold standard method to determine HBR or human landing collection (HLC) [23]. However, it is technically difficult to replicate and unethical in areas where malaria parasites are resistant to drugs [24] and where other mosquito-borne diseases are common. Indoor spray collection and exit trap have been used in some cases but are less sensitive as the anophelines could be less directly associated with feeding on humans [16,24]. The Centers for Disease Control (CDC) light trap hang nearby sleeping people, at night, can also be used to estimate HBR as it catches mosquitoes that attempt to feed on humans [22,25,26]. However, the relationship between a CDC light trap catch and a HLC varies by locality based on the behaviour of the local vectors. SR is the proportion of vectors that carry Plasmodium sporozoites in their salivary glands. Anophelines can be diagnosed for sporozoite infection by dissecting their salivary glands [23], by polymerase chain reaction (PCR) [27] or by ELISA [19] of their thorax and head. In the present study, human blood indices and entomological inoculation rates of anophelines was assessed in a highland malarious area of south-central Ethiopia [28,29].

\section{Methods}

\section{Study area}

Adult anopheline sampling was undertaken along a highland transect of south-central Ethiopia consisting of Hobe (low altitude), Dirama (mid altitude) and Wurib (high altitude) villages once per month for 24 months (July 2008 to June 2010). The villages are located at average elevations of $1,800 \mathrm{~m}, 2,000 \mathrm{~m}$ and 2,200 m, respectively. The low altitude village $\left(\mathrm{N}=08^{0} 01^{\prime} .912\right.$; $\left.\mathrm{E}=038^{0} 29^{\prime} .179\right)$ is adjacent to Odamo stream, the mid $\left(\mathrm{N}=08^{0} 10^{\prime} .061 ; \mathrm{E}=038^{0} 25^{\prime} .142\right)$ to Akamuja stream and the high $\left(\mathrm{N}=08^{0} 04^{\prime} .877 ; \mathrm{E}=038^{0} 17^{\prime} .991\right)$ to Assas stream and Beko Swamp. The streams serve as permanent anopheline breeding habitats during dry seasons [30]. The average annual rainfall of the area is $1,135 \mathrm{~mm}$ while the annual average minimum and maximum temperature is $11.5^{\circ} \mathrm{C}$ and $25^{\circ} \mathrm{C}$ respectively. The average number of occupants per house in the study villages is 4.3 and the inhabitants keep their small number of livestock in their residential houses during the night. Most of the houses were constructed of mud plastered wood and thatched roof. Like the rest of the country, malaria vector control is one of the strategies for the prevention and control of the disease and activities include implementation of LLINs (PermaNet ${ }^{\circledR}$ ) in the low and mid altitude villages and a once per year indoor residual spraying in the low altitude village (personal communication with district health officers). During the study period, LLINs ownership was $28.5 \%$ (Woyessa, personal communication).

\section{Collection, identification and processing of anopheline mosquitoes}

Anophelines were sampled using CDC light traps (John W. Hock Ltd, Gainesville, FL., USA) and pyrethroid space spray collections (PSCs) from indoors and artificial pit traps from outdoors [23]. In each village, CDC light traps were set running from 6:00 pm to 
6:00 am for two consecutive nights in 10 houses (one trap/ house) and the same was repeated in another 10 houses resulting in $40 \mathrm{CDC}$ trap-nights per village per month. A trap was hung next to occupants' foot sleeping under untreated mosquito net about one metre above the ground $[23,31]$ and the trapped female anophelines were collected in the morning by mouth aspirator. PSC was made in the morning (7:00 am to 8:30 am) in ten randomly selected houses in each village once every month. Before spraying, occupants and their domestic animals left the house. In addition, utensils used for food, food, drinking water and clothes were taken out of houses, house apertures carefully covered with clothes, and the available floor was entirely covered by $2-3$ white plastic sheets (each having area of $4 \mathrm{~m} \times 5 \mathrm{~m}$ ). Spraying was made by KILIT ${ }^{\mathrm{TM}}$ insecticide aerosol (Miswa Chemicals LTD, Caswell Road, Brackmills, Northampton, NN4 7PW England) according to the manufacturer's instruction and collectors waited outside for about $15 \mathrm{~min}$. The sheet was then carefully taken out of the house and knocked down mosquitoes were collected using forceps. Five pit traps, constructed in shaded areas, were used for outdoor resting mosquito collection in each village. Each pit shelter was $1.5 \mathrm{~m}$ deep, $1.2 \mathrm{~m}$ long and $1 \mathrm{~m}$ wid. In each pit, four small horizontal cavities of $0.3 \mathrm{~m}$ deep were dug out from $0.5 \mathrm{~m}$ above the bottom on the walls. Anophelines resting in pit shelters were collected by mouth held aspirator using torch as light source.

Female anophelines from all catches were counted, their abdominal status determined [fresh fed (FF), gravid (GR) or unfed (UF)] and identified morphologically to species under stereoscopic dissecting microscope $[23,32]$. Unfed anophelines were dissected and their parity determined microscopically as either parous or nulliparous based on changes in their ovarian tracheal system [23]. Each mosquito was kept in a labelled $1.5 \mathrm{ml}$ Eppendorf tube containing silica gel desiccant and cotton. Samples were stored at room temperature while in the field and in $-20^{\circ} \mathrm{C}$ refrigerator at the main laboratory in Addis Ababa until used. FF anophelines were used for blood meal source identification while those of GRs and parous females were used for sporozoite rate determination.

\section{Identification of Anopheles gambiae sibling species by polymerase chain reaction (PCR)}

About $12.5 \%$ of the Anopheles gambiae s.l were selected randomly and identified to their sibling species using species specific polymerase chain reaction (PCR) [33]. A leg was removed from each mosquito and mixed with $12.5 \mu \mathrm{l}$ PCR master mix (containing 10x dNTPs, $\mathrm{MgCl}_{2}$ Solution, QD primer, UN Primer, GA primer, ME primer, AR primer, deionized water and RTag) in $0.2 \mathrm{ml}$ PCR tube, centrifuged for $20 \mathrm{~s}-20 \mathrm{~min}$ at $16 \mathrm{~K} \mathrm{r.p.m}$. and amplified in a PCR apparatus (PTC- $100^{\mathrm{TM}}$ Programmable Thermo cycler, MJ Research, Inc., USA) with PCR cycle condition $\left(95^{\circ} \mathrm{C} / 5 \mathrm{~min} \times 1\right.$ cycle; $\left[95^{\circ} \mathrm{C} / 30 \mathrm{~s}, 50^{\circ} \mathrm{C} /\right.$ $\left.30 \mathrm{~s}, 72^{\circ} \mathrm{C} / 30 \mathrm{~s}\right] \times 30$ cycles; $72^{\circ} \mathrm{C} / 5 \mathrm{~min} \times 1$ cycle; $4^{\circ} \mathrm{C}$ hold). $5 \mu \mathrm{l}$ PCR product loaded with $2 \mu \mathrm{l}$ loading dye and $4 \mu \mathrm{l}$ DNA ladder were electrophoresed through a $2 \%$ agarose-tris-borate-EDTA containing ethidium bromide gel (with $100 \mathrm{~V}$ and $150 \mathrm{~mA}$ power source) and visualized under UV light box (Alpha Innotech, MultiImage ${ }^{\text {тм }}$, Light Cabinet, Pacific Image Electronics Co. Ltd, Taiwan).

\section{Blood meal source identification and human blood index determination}

FF anophelines, from all catches, were assayed for human and bovine blood antigens simultaneously by ELISA [19]. Abdomen of each FF mosquito was ground in $50 \mu \mathrm{L}$ phosphate-buffered saline (PBS) and final volume brought to $200 \mu \mathrm{L}$ with PBS buffer. $50 \mu \mathrm{L}$ of the triturate was coated in duplicate wells on two separate U-bottomed 96-well microtitre plates simultaneously: one plate for human blood meal identification and the other for bovine. Plates were incubated overnight at room temperature and washed twice with PBS-Tween 20. $50 \mu \mathrm{L}$ peroxidase-conjugated anti-human IgG was added in the first plate and the same volume of peroxidase-conjugated anti-bovine IgG in the second plate incubated for one hour at room temperature and washed thrice with PBS-Tween 20. Finally $100 \mu \mathrm{L}$ ABTS peroxidase substrate was added, incubated at room temperature for $30 \mathrm{~min}$ and observed for green colour reaction visually and absorbance read at $405 \mathrm{~nm}$ (by MRX Microplate Reader, Dynex Technologies, 14340 Sullyfield Circle, Chantilly, VA. 20151-1683, USA). Positive control (either human or bovine blood meal) and negative controls (abdomen of laboratory-bred UF $A n$. arabiensis) were included in each plate. Human blood index (HBI) and bovine blood index (BBI) of each anopheline species was determined by dividing human fed and cattle fed anophelines respectively to the total tested [13].

\section{Sporozoite rate (SR) and entomological inoculation rate (EIR) determination}

Dried head and thorax of GR or parous mosquito, from all catches, were carefully separated from the abdomen and tested for $P$. falciparum and $P$. vivax circumsporozoite proteins (CSPs) simultaneously [34,35]. Three U-bottomed 96-well micro titre plates were coated separately with $50 \mu \mathrm{L}$ solution of P. falciparum, P. vivax-210 and P. vivax-247 monoclonal antibodies (MAB) respectively and incubated at room temperature overnight. Contents of plates were drained, washed three times with PBS-Tween 20, filled with 
$200 \mu \mathrm{L}$ blocking buffer (BB) and incubated for one hour at room temperature. During the incubation period, mosquitoes were grounded individually in $50 \mu \mathrm{L}$ boiled casein containing Igepal CA-630 and the final volume brought to $250 \mu \mathrm{L}$ with BB. BB was removed from plates and $50 \mu \mathrm{L}$ of each mosquito triturate was added to each of the three test wells. CSP positive sample and laboratory-bred $A n$. arabiensis were used as positive and negative controls, respectively. Plates were incubated for two hours and washed with PBS-Tween 20 twice. $50 \mu \mathrm{L}$ aliquots of homologous peroxidase-conjugated $\mathrm{MAB}(0.05 \mu \mathrm{g} / 50 \mu \mathrm{L} \quad \mathrm{BB})$ were added to each triplicate well in the plates and incubated for one hour. Plates were washed thrice with PBS-Tween 20, $100 \mu \mathrm{L}$ ABTS peroxidase substrate added per well and incubated for 30 and or $60 \mathrm{~min}$. Plates were observed visually for green colour and also their optical density determined at $405 \mathrm{~nm}$ in the micro plate reader. Samples with green colour and with optical density values of greater than two times the average optical density of the negative controls were considered sporozoite positive. Positive samples were retested for confirmation. The $P$. falciparum and $P$. vivax SRs of each Anopheles species was determined by dividing $P$. falciparum and $P$. vivax positive anophelines respectively to the total tested. SR was determined for CDC light trap catches and also for PSCs separately.

Since no human landing catch (HLC) was performed, the daily EIR was estimated based on CDC light trap and PSC. For CDC based EIR, the factor determined for An. arabiensis in Zambia [22], where a CDC represents 1.91 of an HLC indoors was used. Thus, $1.91 \times$ (no. sporozoite positive ELISAs/ no. mosquitoes tested) $\times$ (no. mosquitoes collected by CDC/no. CDC catches).

Similarly, the daily EIR based on PSC was calculated according to WHO [36] as (no. FF mosquitoes caught by PSC/no. human occupants who spent the night in the sprayed house $) \times$ (no. uman fed mosquitoes/no. mosquitoes tested for human blood meal) $\times$ (no. sporozoite positive ELISAs/no. mosquitoes tested).

\section{Statistical analysis}

Data entry and analysis was made using SPSS version 16.0 soft ware (SPSS Inc., Chicago, IL). The significance of differences between proportions of human fed and bovine fed anophelines was analysed using Chi-square test. The daily EIR was multiplied by the number of days of the corresponding month to get estimated monthly EIR in each village. Then, the monthly EIRs in each village were summed up to obtain the annual EIR [16].

\section{Ethical issues}

The investigation was ethically approved by the Ethical Committee of the Faculty of Medicine of Addis Ababa University and The National Health Research Ethics
Review Committee (NERC) of Ethiopia with reference number RDHE/48-85/2009.

\section{Results}

Composition and blood meal source of Anopheles species A total of 4558 adult female Anopheles mosquitoes were caught of which Anopheles gambiae s.l (=An. arabiensis) was the most prevalent (53.3\%) followed by Anopheles demeilloni (26.3\%), Anopheles christyi (8.9\%), Anopheles pharoensis (7.9\%) and Anopheles cinereus (3.6\%) (Table 1). PCR identification of the sample of $A n$. gambiae s.l $(\mathrm{n}=305)$ showed all to be $A n$. arabiensis; hence all other An. gambiae s.l samples were regarded to be An. arabiensis. Anopheles arabiensis was highest in the low altitude village $(86.0 \%)$ and lowest in the high altitude village (1.2\%). Similarly, An. pharoensis was highest in the low altitude village (13.4\%) and lowest in the high altitude village $(0.3 \%)$. On the other hand, catches of $A n$. christyi, An. demeilloni and An. cinereus were highest in the high altitude village and very low or scarce in the low altitude village.

In almost all species and villages (Table 1), FF anophelines were predominant indoors (in CDC and PSC collections) despite the use of nets by the occupants, whereas these were very low outdoors (in pit shelter collections). Furthermore, UF females of An. arabiensis and $A n$. pharoensis were surprisingly the lowest indoors in CDC collections. Likewise, significant number of GR females was collected indoors.

Table 2 reveals the blood meal sources of different anopheline species in south-central Ethiopia. In CDC traps, $A n$. arabiensis had human blood index (HBI) ranging from $32 \%$ in the low altitude village to $57 \%$ in the high altitude village (average $\mathrm{HBI}=34 \%$ ). In $\mathrm{PSC}$, the same species had HBI of $25 \%$ in the high altitude village to $31.5 \%$ in the low altitude village (average $\mathrm{HBI}=31 \%$ ). In outdoors, very small number of FF An. arabiensis were caught and tested from the low altitude village only, which had $66.7 \%$ HBI. Thus, the overall HBI of $A n$. arabiensis in the study area was $32.2 \%$. Regarding An. pharoensis, the $\mathrm{HBI}$ in $\mathrm{CDC}$ traps ranged from $19 \%$ in the low altitude village to $21.4 \%$ in the mid altitude village (average $\mathrm{HBI}=18.8$ ), whereas its values in the PSC ranged from $25 \%$ in the low to $0 \%$ in the mid village (average $\mathrm{HBI}=17.4 \%$ ); no specimen was analysed from pit shelters. Thus, the overall HBI of An. pharoensis was $18.6 \%$ in the study area.

Regarding the zoophilic feeding behaviour of the two species, An. arabiensis had bovine blood feeds of $14.3 \%$ in the high elevation village to $39.1 \%$ in the low (average $=38 \%$ ) in CDC catches, while the values ranged from $0 \%$ in the high altitude village to $49 \%$ in the mid-altitude village (average $=40.5 \%$ ) in PSCs. In outdoor catches, only $33.3 \%$ were bovine fed. Thus, 
Table 1 Anopheline species and their abdominal status by village and collection method in south-central Ethiopia, July 2008- June 2010

\begin{tabular}{|c|c|c|c|c|c|c|c|c|c|c|c|}
\hline \multirow[t]{2}{*}{ Village } & \multirow[t]{2}{*}{ Species } & \multirow[t]{2}{*}{ Total } & \multicolumn{3}{|c|}{ CDC } & \multicolumn{3}{|c|}{ PSC } & \multicolumn{2}{|c|}{ Pit shelter } & \multirow[b]{2}{*}{$\overline{G R}$} \\
\hline & & & $\overline{U F}$ & $\mathrm{FF}$ & $\overline{G R}$ & $\overline{U F}$ & $\mathrm{FF}$ & $\overline{G R}$ & $\overline{U F}$ & $\mathrm{FF}$ & \\
\hline \multirow[t]{5}{*}{ Hobe $(n=2442)$} & An. arabiensis & 2101 & 127 & 436 & 272 & 49 & 771 & 427 & 10 & 3 & 6 \\
\hline & An. pharoensis & 328 & 34 & 212 & 64 & 0 & 16 & 2 & 0 & 0 & 0 \\
\hline & An. christyi & 7 & 0 & 2 & 5 & 0 & 0 & 0 & 0 & 0 & 0 \\
\hline & An. cinereus & 5 & 0 & 2 & 1 & 0 & 1 & 1 & 0 & 0 & 0 \\
\hline & An. demeilloni & 1 & 0 & 0 & 1 & 0 & 0 & 0 & 0 & 0 & 0 \\
\hline \multirow[t]{5}{*}{ Dirama $(n=481)$} & An. arabiensis & 311 & 22 & 65 & 41 & 6 & 118 & 59 & 0 & 0 & 0 \\
\hline & An. pharoensis & 26 & 0 & 14 & 3 & 1 & 7 & 1 & 0 & 0 & 0 \\
\hline & An. christyi & 26 & 5 & 12 & 5 & 0 & 0 & 3 & 0 & 1 & 0 \\
\hline & An. cinereus & 23 & 4 & 12 & 1 & 1 & 3 & 2 & 0 & 0 & 0 \\
\hline & An. demeilloni & 95 & 22 & 53 & 14 & 1 & 2 & 1 & 0 & 0 & 2 \\
\hline \multirow[t]{6}{*}{ Wurib (n=1635) } & An. arabiensis & 19 & 3 & 6 & 5 & 0 & 4 & 1 & 0 & 0 & 0 \\
\hline & An. pharoensis & 5 & 0 & 4 & 1 & 0 & 0 & 0 & 0 & 0 & 0 \\
\hline & An. christyi & 373 & 91 & 149 & 54 & 2 & 45 & 20 & 3 & 2 & 7 \\
\hline & An. cinereus & 135 & 14 & 56 & 25 & 3 & 13 & 8 & 2 & 2 & 12 \\
\hline & An. demeilloni & 1103 & 128 & 588 & 117 & 9 & 90 & 33 & 22 & 30 & 86 \\
\hline & Total & 4558 & 450 & 1611 & 609 & 72 & 1070 & 558 & 37 & 38 & 113 \\
\hline
\end{tabular}

Note: $n=$ total anophelines collected per village; $C D C=$ Centers for Disease Control light trap; $P S C s=$ pyrethriod spray catches; UF=Unfed; $F F=F r e s h$ Fed; $G R=G r a v i d$.

the overall zoophilic feeding pattern (index) was about $39.6 \%$ in the study area. For An. arabiensis, its overall BBI was not statistically different from the HBI.

Similarly, $A n$. pharoensis which was absent in the high altitude village had $55.8 \%$ and $64.3 \%$ of similar bovine feeding rates in the low and mid villages in CDC catches, respectively (average $=51.2 \%$ ). It also had BBIs of $43.8 \%$ in the low and $85.7 \%$ in the mid village (average $=56.5 \%$ ). In the absence of bovine feeds outdoors, its overall bovine feeding rate was $55.9 \%$ showing to have a

Table 2 Blood meal sources of indoor and outdoor resting anophelines of three highland villages (Hobe, Dirama and Wurib) of south-central Ethiopia, July 2008- June 2010

\begin{tabular}{|c|c|c|c|c|c|c|c|c|c|c|c|c|c|c|c|}
\hline \multirow{2}{*}{$\begin{array}{l}\text { Village and } \\
\text { anopheline }\end{array}$} & \multicolumn{5}{|c|}{ CDC } & \multicolumn{5}{|c|}{ PSC } & \multicolumn{5}{|c|}{ Pit shelter } \\
\hline & $n$ & $\mathrm{HBI}$ & $\mathrm{BBI}$ & Mix & Un & $\mathrm{n}$ & $\mathrm{HBI}$ & BBI & Mix & Un & $n$ & $\mathrm{HBI}$ & BBI & Mix & Un \\
\hline \multicolumn{16}{|l|}{ Hobe } \\
\hline An. arabiensis & 422 & 32 & 39.1 & 13.7 & 15.2 & 723 & 31.5 & 39.4 & 12.2 & 16.9 & 3 & 66.7 & 33.3 & 0 & 0 \\
\hline An. pharoensis & 206 & 18.9 & 55.8 & 14.6 & 11.6 & 16 & 25 & 43.8 & 25 & 6.2 & 0 & 0 & 0 & 0 & 0 \\
\hline \multicolumn{16}{|l|}{ Dirama } \\
\hline An. arabiensis & 64 & 43.7 & 34.4 & 12.5 & 9.4 & 114 & 28.1 & 49.1 & 7 & 15.8 & 0 & 0 & 0 & 0 & 0 \\
\hline An. pharoensis & 14 & 21.4 & 64.3 & 14.3 & 0 & 7 & 0 & 85.7 & 14.3 & 0 & 0 & 0 & 0 & 0 & 0 \\
\hline An. christyi & 9 & 11.1 & 66.7 & 11.1 & 11.1 & 1 & 0 & 100 & 0 & 0 & 1 & 100 & 0 & 0 & 0 \\
\hline An. cinereus & 10 & 20 & 60 & 20 & 0 & 2 & 50 & 50 & 0 & 0 & 0 & 0 & 0 & 0 & 0 \\
\hline An. demeilloni & 41 & 9.8 & 70.7 & 2.4 & 17.1 & 1 & 0 & 0 & 0 & 0 & 0 & 0 & 0 & 0 & 0 \\
\hline \multicolumn{16}{|l|}{ Wurib } \\
\hline An. arabiensis & 6 & 57.1 & 14.3 & 0 & 28.6 & 4 & 25 & 0 & 25 & 50 & 0 & 0 & 0 & 0 & 0 \\
\hline An. christyi & 125 & 26.4 & 55.2 & 8 & 10.4 & 37 & 27 & 48.6 & 18.8 & 5.6 & 2 & 50 & 50 & 0 & 0 \\
\hline An. cinereus & 49 & 20.4 & 51 & 14.3 & 14.3 & 12 & 16.7 & 66.7 & 8.3 & 8.3 & 1 & 100 & 0 & 0 & 0 \\
\hline An. demeilloni & 471 & 11.5 & 69 & 5.7 & 13.8 & 70 & 5.7 & 72.9 & 1.4 & 20 & 22 & 9.1 & 68.2 & 0 & 22.7 \\
\hline
\end{tabular}


more zoophilic behaviour than that of An. arabiensis. However, the overall BBI of An. arabiensis was not significantly different from that of the BBI of $A n$. pharoensis.

Apart from either of the two main blood meal sources (human and bovine), a small proportions of the two species also had mixed feeding patterns ranging from 0 to $14 \%$ in CDC traps and from 7 to $25 \%$ in PSCs with averages of $12.2 \%$ for An. arabiensis and $15 \%$ for An. pharoensis. Furthermore, 15.2\% An. arabiensis and $11.6 \%$ of $A n$. pharoensis from Hobe had blood meals of undetermined origin; no such blood meals were detected in outdoor pit shelters since specimens were generally low. Other non-vector anophelines (An. christyi, An. cinereus and An. demeilloni) caught indoors or outdoors in all villages exhibited far more zoophilic behaviour (48.6\% to $100 \%$ ) than anthropophilic behaviours.

\section{Sporozoite rates}

A total of 1117 indoor caught anophelines, representing five species, were tested for Plasmodium circumsporozoite proteins (CSPs) (Table 3). Sporozoites were only detected in 18 mosquitoes belonging to two species (An. arabiensis and An. pharoensis) collected from the low and mid- altitude villages. A total of 819 An. arabiensis tested from both CDC and PSC had overall $P$. vivax and P. falciparum sporozoite rates of $1.7 \%$ and $0.2 \%$, respectively. In the low altitude village, the $P$. vivax sporozoite rate in the same species was 3\% and 0.7\% from CDC and PSC, respectively, where highest number of An. arabiensis was caught and analysed. The $P$. falciparum sporozoite rate for the same mosquito in the village was $0.3 \%$ and $0.2 \%$ in the $\mathrm{CDC}$ and PSC, respectively. In the mid altitude village, where small number of $A n$. arabiensis were analysed, the $P$. vivax rates were $2.5 \%(1 / 40)$ (CDC) and 1.7\% (1/58) (PSC).

Similarly, analysis of only $79 \mathrm{An}$. pharoensis from all the three villages resulted in an overall $P$. vivax rate of $2.5 \%(2 / 79)$ with no $P$. falciparum infection. Most of the An. pharoensis caught and analysed was from the low altitude village where $P$. vivax sporozoite rate was $1.4 \%(1 / 71)$ in $\mathrm{CDC}$ and $50 \%(1 / 2)$ in PSC. None of the very few mosquitoes tested in the two other villages were positive for either of the two Plasmodium sporozoites.

Although sporozoite infections were generally low, they were higher among CDC light trap catches (Table 4) than PSC catches (Table 5). Among the An. arabiensis caught by the CDC trap, the daily $P$. vivax sporozoite

Table 3 Sporozoite infection rates of anophelines in three highland villages of south-central Ethiopia, July 2008- June 2010

\begin{tabular}{|c|c|c|c|c|c|c|c|c|c|c|c|}
\hline \multirow{2}{*}{$\begin{array}{l}\text { Villages and } \\
\text { parameters }\end{array}$} & \multicolumn{2}{|c|}{ An. arabiensis } & \multicolumn{2}{|c|}{ An. pharoensis } & \multicolumn{2}{|c|}{ An. demeilloni } & \multicolumn{2}{|c|}{ An. christyi } & \multicolumn{2}{|c|}{ An. cinereus } & \multirow[t]{2}{*}{ Total } \\
\hline & $\overline{C D C}$ & PSC & $\overline{C D C}$ & PSC & $\overline{C D C}$ & PSC & $\mathrm{CDC}$ & PSC & $\mathrm{CDC}$ & PSC & \\
\hline \multicolumn{12}{|l|}{ Hobe } \\
\hline No. tested & 300 & 416 & 71 & 2 & 0 & 0 & 1 & 0 & 1 & 0 & 791 \\
\hline No. PvS+ (\%) & $9(3)$ & $3(0.7)$ & $1(1.4)$ & $1(50)$ & 0 & 0 & 0 & 0 & 0 & 0 & $14(1.8)$ \\
\hline No. PfS+ (\%) & $1(0.3)$ & $1(0.2)$ & 0 & 0 & 0 & 0 & 0 & 0 & 0 & 0 & $2(0.3)$ \\
\hline \multicolumn{12}{|l|}{ Dirama } \\
\hline No. tested & 40 & 58 & 4 & 1 & 12 & 0 & 3 & 2 & 1 & 3 & 124 \\
\hline No. PvS+ (\%) & $1(2.5)$ & $1(1.7)$ & 0 & 0 & 0 & 0 & 0 & 0 & 0 & 0 & $2(1.6)$ \\
\hline No. PfS+ (\%) & 0 & 0 & 0 & 0 & 0 & 0 & 0 & 0 & 0 & 0 & 0 \\
\hline \multicolumn{12}{|l|}{ Wurib } \\
\hline No. tested & 4 & 1 & 1 & 0 & 85 & 22 & 45 & 10 & 28 & 6 & 202 \\
\hline No. PvS+ (\%) & 0 & 0 & 0 & 0 & 0 & 0 & 0 & 0 & 0 & 0 & 0 \\
\hline No. PfS+ (\%) & 0 & 0 & 0 & 0 & 0 & 0 & 0 & 0 & 0 & 0 & 0 \\
\hline \multicolumn{12}{|l|}{ Total } \\
\hline No. tested & 344 & 475 & 76 & 3 & 97 & 22 & 49 & 12 & 30 & 9 & 1117 \\
\hline No. PvS+ (\%) & $10(2.9)$ & $4(0.8)$ & $1(1.3)$ & $1(33)$ & 0 & 0 & 0 & 0 & 0 & 0 & $16(1.4)$ \\
\hline No. PfS+ (\%) & $1(0.3)$ & $1(0.2)$ & 0 & 0 & 0 & 0 & 0 & 0 & 0 & 0 & $2(0.3)$ \\
\hline \multicolumn{12}{|l|}{ Overall } \\
\hline No. tested & 819 & & 79 & & 119 & & 61 & & 39 & & 1117 \\
\hline No. PvS+ (\%) & $14(1.7)$ & & $2(2.5)$ & & 0 & & 0 & & 0 & & $16(1.4)$ \\
\hline No. PfS+ (\%) & $2(0.2)$ & & 0 & & 0 & & 0 & & 0 & & $2(0.3)$ \\
\hline
\end{tabular}

$P v S+(\%)=$ number $P$. vivax sporozoite positive (rate in percent) $;$ PfSR (\%) = number $P$. falciparum sporozoite positive (rate in percent). 
Table 4 CDC light trap based assessment of sporozoite and entomological inoculation rates in two highland villages of south-central Ethiopia, July 2008- June 2010

\begin{tabular}{|c|c|c|c|c|c|c|c|c|}
\hline \multirow[t]{2}{*}{$\begin{array}{l}\text { Study } \\
\text { period }\end{array}$} & \multicolumn{4}{|c|}{$\begin{array}{c}\text { Hobe } \\
\text { An. arabiensis }\end{array}$} & \multicolumn{2}{|c|}{$\begin{array}{c}\text { Hobe } \\
\text { An. pharoensis }\end{array}$} & \multicolumn{2}{|c|}{$\begin{array}{c}\text { Dirama } \\
\text { An. arabiensis }\end{array}$} \\
\hline & Daily PvSR & Monthly PvEIR & Daily PfSR & Monthly PfEIR & Daily PvSR & Monthly PvEIR & Daily PvSR & Monthly PvEIR \\
\hline Jul 2008 & 0 & 0 & 0 & 0 & 0 & 0 & 0 & 0 \\
\hline Aug 2008 & 0.17 & 6.23 & 0 & 0 & 0 & 0 & 0 & 0 \\
\hline Sep 2008 & 0 & 0 & 0 & 0 & 0 & 0 & 0 & 0 \\
\hline Oct 2008 & 0.04 & 4.00 & 0 & 0 & 0 & 0 & 0 & 0 \\
\hline Nov 2008 & 0 & 0 & 0 & 0 & 0 & 0 & 0 & 0 \\
\hline Dec 2008 & 0 & 0 & 0 & 0 & 0 & 0 & 0 & 0 \\
\hline Jan 2009 & 0 & 0 & 0 & 0 & 0 & 0 & 0 & 0 \\
\hline Feb 2009 & 0 & 0 & 0 & 0 & 0 & 0 & 0 & 0 \\
\hline Mar 2009 & 0.05 & 3.85 & 0 & 0 & 0 & 0 & 0 & 0 \\
\hline Apr 2009 & 0.03 & 11.56 & 0 & 0 & 0 & 0 & 0 & 0 \\
\hline May 2009 & 0.03 & 7.31 & 0.02 & 3.66 & 0 & 0 & 0 & 0 \\
\hline Jun 2009 & 0 & 0 & 0 & 0 & 0 & 0 & 0 & 0 \\
\hline Year I Total & 0.32 & $32.95^{*}$ & 0.02 & $3.66^{*}$ & 0 & $0^{*}$ & 0 & $0^{*}$ \\
\hline Jul 2009 & 0 & 0 & 0 & 0 & 1 & 2.3 & 0 & 0 \\
\hline Aug 2009 & 0 & 0 & 0 & 0 & 0 & 0 & 0.5 & 2.58 \\
\hline Sep 2009 & 0 & 0 & 0 & 0 & 0 & 0 & 0 & 0 \\
\hline Oct 2009 & 0 & 0 & 0 & 0 & 0 & 0 & 0 & 0 \\
\hline Nov 2009 & 0 & 0 & 0 & 0 & 0 & 0 & 0 & 0 \\
\hline Dec 2009 & 0 & 0 & 0 & 0 & 0 & 0 & 0 & 0 \\
\hline Jan 2010 & 0 & 0 & 0 & 0 & 0 & 0 & 0 & 0 \\
\hline Feb 2010 & 0 & 0 & 0 & 0 & 0 & 0 & 0 & 0 \\
\hline Mar 2010 & 0 & 0 & 0 & 0 & 0 & 0 & 0 & 0 \\
\hline Apr 2010 & 0 & 0 & 0 & 0 & 0 & 0 & 0 & 0 \\
\hline May 2010 & 0.2 & 14.5 & 0 & 0 & 0 & 0 & 0 & 0 \\
\hline Jun 2010 & 0 & 0 & 0 & 0 & 0 & 0 & 0 & 0 \\
\hline Year II Total & 0.2 & $14.5^{*}$ & 0 & $0^{*}$ & 1 & $2.3^{*}$ & 0.5 & $2.58^{*}$ \\
\hline
\end{tabular}

PVEIR=Plasmodium vivax entomological inoculation rate; PfEIR=P. falciparum entomological inoculation rate; ${ }^{*}=$ annual EIR.

rate was highest in May 2010 (which was 0.2) and was lower or zero during most of the months in the low altitude village (Table 4) where most of the sporozoites were observed. No distinct seasonal pattern was apparent for An. pharoensis since only two mosquitoes were found positive for $P$. vivax during the whole study period. Generally, very low $P$. falciparum sporozoite rate were observed in all catches and study villages.

\section{Entomological inoculation rates (EIR)}

In the absence of direct human landing catches, EIR for each village was estimated based on the sampling methods employed (CDC and PSCs). However, a small number of mosquitoes were found sporozoite positive on both catches and in all villages. This resulted in low EIR estimates varying from 0 (in most months) to
14.5 (May 2010) monthly P. vivax infectious bites of An. arabiensis in the low altitude village (Hobe) based on the CDC trap catches (Table 4), while it had only 2.58 in the mid-altitude village (Dirama) in August 2009. Based on CDC based EIR estimates, there was evidence of $P$. vivax transmission in August and October of 2008, in March, April and May of 2009, and in May 2010 coinciding with small rainy seasons of the year in the area.

Although the number of An. arabiensis caught by PSC $(n=1,247)$ was much higher than the number caught by CDC traps ( $\mathrm{n}=835)$, in the low altitude village, the total number of sporozoite infected mosquitoes was very low in the PSC (Table 5). Monthly P. vivax EIRs of 0.13 and 0.73 were observed in October 2008 and in June 2009 in the village. In addition, there was P. falciparum EIR of 
Table 5 PSC based assessment of sporozoite and entomological inoculation rates in two highland villages of south-central Ethiopia, July 2008- June 2010

\begin{tabular}{|c|c|c|c|c|c|c|c|c|}
\hline \multirow[b]{2}{*}{ Study period } & \multicolumn{4}{|c|}{$\begin{array}{c}\text { Hobe } \\
\text { An. arabiensis }\end{array}$} & \multicolumn{2}{|c|}{$\begin{array}{c}\text { Hobe } \\
\text { An. pharoensis }\end{array}$} & \multicolumn{2}{|c|}{$\begin{array}{c}\text { Dirama } \\
\text { An. arabiensis }\end{array}$} \\
\hline & Daily PvSR & Monthly PvEIR & Daily PfSR & Monthly PfEIR & Daily PvSR & Monthly PvEIR & Daily PvSR & Monthly EIR \\
\hline Jul 2008 & 0 & 0 & 0 & 0 & 0 & 0 & 0 & 0 \\
\hline Aug 2008 & 0 & 0 & 0 & 0 & 0 & 0 & 0 & 0 \\
\hline Sep 2008 & 0 & 0 & 0 & 0 & 0.5 & 0.32 & 0 & 0 \\
\hline Oct 2008 & 0.08 & 0.13 & 0 & 0 & 0 & 0 & 0 & 0 \\
\hline Nov 2008 & 0 & 0 & 0 & 0 & 0 & 0 & 0 & 0 \\
\hline Dec 2008 & 0 & 0 & 0 & 0 & 0 & 0 & 0 & 0 \\
\hline Jan 2009 & 0 & 0 & 0 & 0 & 0 & 0 & 0 & 0 \\
\hline Feb 2009 & 0 & 0 & 0 & 0 & 0 & 0 & 0 & 0 \\
\hline Mar 2009 & 0 & 0 & 0 & 0 & 0 & 0 & 0 & 0 \\
\hline Apr 2009 & 0 & 0 & 0 & 0 & 0 & 0 & 0 & 0 \\
\hline May 2009 & 0 & 0 & 0 & 0 & 0 & 0 & 0 & 0 \\
\hline Jun 2009 & 0.03 & 0.73 & 0 & 0 & 0 & 0 & 0 & 0 \\
\hline year I Total & 0.11 & $0.86^{*}$ & 0 & $0^{*}$ & 0.5 & $0.32^{*}$ & 0 & $0^{*}$ \\
\hline Jul 2009 & 0 & 0 & 0 & 0 & 0 & 0 & 0 & 0 \\
\hline Aug 2009 & 0 & 0 & 0 & 0 & 0 & 0 & 0 & 0 \\
\hline Sep 2009 & 0 & 0 & 0.04 & 0.93 & 0 & 0 & 0 & 0 \\
\hline Oct 2009 & 0 & 0 & 0 & 0 & 0 & 0 & 0 & 0 \\
\hline Nov 2009 & 0 & 0 & 0 & 0 & 0 & 0 & 0 & 0 \\
\hline Dec 2009 & 0 & 0 & 0 & 0 & 0 & 0 & 0 & 0 \\
\hline $\operatorname{Jan} 2010$ & 0 & 0 & 0 & 0 & 0 & 0 & 0 & 0 \\
\hline Feb 2010 & 0 & 0 & 0 & 0 & 0 & 0 & 0 & 0 \\
\hline Mar 2010 & 0 & 0 & 0 & 0 & 0 & 0 & 0 & 0 \\
\hline Apr 2010 & 0 & 0 & 0 & 0 & 0 & 0 & 0 & 0 \\
\hline May 2010 & 0 & 0 & 0 & 0 & 0 & 0 & 0.09 & 0.2 \\
\hline Jun 2010 & 0 & 0 & 0 & 0 & 0 & 0 & 0 & 0 \\
\hline Year II Total & 0 & $0^{*}$ & 0.04 & $0.93^{*}$ & 0 & $0^{*}$ & 0.09 & $0.2^{*}$ \\
\hline
\end{tabular}

0.93 in September 2009 in the village. While the only $P$. vivax infection in the mid-altitude village in May 2010, resulted in the monthly EIR of 0.2 .

Annual EIRs varied between the first and the second years and also between the low and mid-altitude villages (Table 4). From the CDC light trap collections; there were 3.66 and $0 P$. falciparum infective bites per year per person for An. arabiensis in the years July 2008 to June 2009 and July 2009 to June 2010 respectively in the low altitude village. The corresponding values for $P$. vivax infective bites by $A n$. arabiensis were 33 and 14.5 in the village. In addition, there were 0 and $2.3 P$. vivax infective bites for An. pharoensis in the village during the first year and the second year, respectively. The space spray catch revealed $0.32 P$. vivax infective bites per person for An. pharoensis during the first year with zero value in the second year.

\section{Discussion}

Anopheles arabiensis was the predominant malaria vector followed by An. pharoensis along the altitudinal transect consisting of Hobe (low altitude; $1,800 \mathrm{~m}$ ), Dirama (mid altitude; 2,000 m) and Wurib (high altitude; 2,200 m) villages in south-central Ethiopia. Although sampling was not made for anophelines that could escape through eves and windows, the highest number of $A n$. arabiensis was caught by pyrethroid spray revealing its indoor resting behaviour $[37,38]$. The majority of the anophelines were collected from inside houses which could be associated with the indoor occurrence of blood meal sources, higher indoor temperature and with limited outdoor-resting places [38,39]. Most An. arabiensis and other anopheline species caught indoors (An. pharoensis, An. christyi, $A n$. demeilloni, and An. cinereus) were fresh fed and 
gravid indicating their indoor or outdoor feeding with indoor resting behaviour. The higher number of fresh fed and gravid mosquitoes in the CDC light trap catches might be due to their attraction to CDC light traps and their possible repeated feeding behaviour $[13,22,27]$. The human fed catches by the CDC light traps, despite the presence of nets, might be due to the early biting behaviour of $A n$. arabiensis [40] before bed time and blood feeding on exposed occupants who sleep traditionally on floor mats in which case nets do not provide adequate protection.

The HBI of $A n$. arabiensis was similar to that of its BBI indicating its opportunistic feeding behaviour in the area. Similar feeding preferences are reported from southern Ethiopia where people and livestock either share the same houses or where cattle are kept separate but close to houses during the night [41]. Our result can also be strengthened by the study from Fuchucha village in the Konso District of Ethiopia where cattle- and human-fed $A n$. arabiensis mosquitoes were found to have similar rates of Plasmodium infection [42]. However, the HBI observed in this study is very low compared to the value from human dwellings alone (91.5\%) and higher compared to that from human and bovine mixed dwellings (20.2\%) reported in the country [43]. The variations in the HBI of the vector could result from differences in the relative distance and accessibility of hosts.

The HBI of $A n$. pharoensis observed in this study (18.6\%) is lower than that of An. arabiensis, but is higher compared to that of the Kenya (8.2\%) [13]. In addition, it had the highest mixed human and bovine blood index among the five anopheline species. An experimental study in southern Ethiopia [44] documented similar number of $A n$. pharoensis catches both in human- and cattle-baited traps. Thus, it can be suggested that An. pharoensis of south-central Ethiopia may have a moderately opportunistic feeding behaviour probably due to its similar responsiveness to cattle and human host cues [44]. This tendency of the mosquito to feed on humans increases its vectorial capacity. Anopheles christyi, An. cinereus and $A n$. demeilloni also had considerably high human blood indices depicting their importance as biting nuisances. Anopheles cinereus has previously been reported as a potential vector of malaria in Eritrea [45]. Significant number of blood meals of An. arabiensis, An. pharoensis and other anophelines could not be identified by ELISA, which most could have been identified by PCR [33]. Limitations of primers and reagents hindered the use of such a technique in the study. The quality of some of the blood samples might have also been degraded during storage before analysis. However, the unidentified blood meal sources could be of sheep, goat, donkey, horse, chicken and dogs which are available in the area.
Anopheles arabiensis was the most abundant, most anthropophilic and the most sporozoite laden species proving its role as the primary malaria vector in the area [1]. Very few An. pharoensis $(\mathrm{n}=2)$ were found carrying $P$. vivax sporozoites which might be attributed to its occurrence mainly following the main rainy season. $P$. vivax sporozoite carriage was higher than that of $P$. falciparum which is also similar to previous reports from southern Ethiopia $[41,42,46]$. This describes dominance of vivax malaria transmission over falciparum in the region. It is, therefore, imperative to undertake epidemiological studies on $P$. vivax in view of the current reports that revealed severe clinical manifestation resulting from the infection $[47,48]$.

Annual Plasmodium falciparum infectious bite was lower than 10 in the study villages indicating its unstable transmission intensity $[21,49]$ and risk of epidemics [50]. Apart from this, the study area is a highland fringe where vector density is lower resulting in low transmission intensity compared to typical lowland malarious areas such as in southern Ethiopia [42], Tanzania [51], Eritrea [14], Zambia [16] and Uganda [49]. For example, in southern Ethiopia, more than 45, 000 An. arabiensis were collected in 12 months at a locality with an average altitude ranging from $800 \mathrm{~m}$ to $1,300 \mathrm{~m}$ a.s.l. [42] compared to the present 2,431 An. arabiensis in the two years study time. However, since adult anopheline sampling was undertaken only once per month, this value may underestimate the risk of malaria transmission. Plasmodium falciparum and $P$. vivax infective $A n$. arabiensis bites and $P$. vivax infective $A n$. pharoensis bites decreased starting from the low altitude village to the higher. An increase in altitude is related to a decrease in temperature that limits vector occurrence and development of the parasites in the vector thereby reducing the number of infectious anopheline bites [50,52,53]. Mortality due to malaria was also reported to have a decreasing magnitude with increasing altitude in the area [28].

Recent studies, in the study area [7,54], reported $P$. vivax and $P$. falciparum malaria transmissions at elevations ranging from 2,100 $\mathrm{m}$ to $2,280 \mathrm{~m}$. Although the relationship between EIR and malaria prevalence rate is not direct [20,55], EIR may vary between 0 and 1,500 infective bites per person per year in endemic countries of Africa and is a useful index in assessing malaria endemicity and transmission intensity $[20,49]$. The number of infective bites by both $A n$. arabiensis and An. pharoensis were higher during dry months compared to the rainy months as was observed in western Kenya [56] and eastern Sudan [57]. However, this trend is different from the report in Eritrea [14] where EIR in wet season was nine times higher than in the dry season and also from that of southern Zambia [16], Tanzania [51] and Kenya [58]. This seasonal difference could result from diverse ecological adaptation and 
behavioural changes of An. arabiensis. Malaria infectious bites were observed during the months of August to October and March to June which generally corresponds to the major and minor malaria transmission seasons respectively in the country [59]. This finding suggests that malaria transmission is seasonal and unstable in Hobe, Dirama and Wurib villages of south-central Ethiopia. As in most parts of Ethiopia, the unstable malaria transmission in the study area could result from variations in the meteorological factors, movement of inhabitants from non malarious to malarious areas and vice versa, and human population growth increasing activities that create increased and suitable vector breeding habitats along natural wetlands and foothills [60]. In addition, Plasmodium infectious bites were more frequent in the first study year (July 2008 to June 2009) and decreased from the low elevation village to the suggesting temporal and spatial variation of malaria transmission intensity.

\section{Conclusion}

Anopheles arabiensis was the most prevalent vector of $P$. vivax and $P$. falciparum malaria along a southcentral highland transect of Ethiopia consisting of Hobe (low altitude), Dirama (mid altitude) and Wurib (high altitude) villages followed by An. pharoensis. Both anopheline species fed on human and bovine of which the first was opportunistic feeder while the second being moderately anthropophilic. The annual EIRs were generally lower compared to typical endemic areas and showed a decreasing trend from the low altitude village to the high altitude village.

\section{Competing interests}

The authors declare that they have no competing interests.

\section{Authors' contributions \\ AA designed the study, collected data in the field, carried out the data analysis and wrote the first draft of the manuscript. TGM participated in the study design, interpretation of the results and editing the manuscript. MB participated in the conception of the study, in the study design and editing the manuscript. BL conceived the idea for the study and took part in the study design, data entry and analysis, data interpretation and editing the manuscript. All authors have read and approved the final manuscript.}

\section{Acknowledgements \\ This study obtained financial support from NUFU (Project No: NUFUPRO- 2007/10121). Aklilu Lemma Institute of Pathobiology, Addis Ababa University is duly acknowledged for providing field vehicles and for facilitating the study. We thank Yohannes Negash and Nega Nigussie for their technical assistance both in the field and in the laboratory. We also thank the anonymous reviewers for the improvement of this manuscript.}

Received: 20 December 2012 Accepted: 19 February 2013 Published: 23 February 2013

\section{References}

1. Federal Democratic Republic of Ethiopia Ministry of Health (FDRE-MoH): FDRE-MoH National Five-Year Strategic Plan for Malaria Prevention and Control in Ethiopia (2006-2010). Addis Ababa, Ethiopia: 2006.
2. Kibret S, Alemu Y, Boelee E, Tekie H, Alemu D, Petros B: The impact of a small-scale irrigation scheme on malaria transmission in Ziway area, Central Ethiopia. Trop Med Int Health 2010, 15:41-50.

3. Ghebreyesus TA, Haile M, Witten KH, Getachew A, Yohannes AM, Yohannes M, Teklehaimanot HD, Lindsay SW, Byass P: Incidence of malaria among children living near dams in northern Ethiopia: community based incidence survey. BMJ 1999, 319:663-666.

4. Yohannes M, Haile M, Ghebreyesus TA, Witten KH, Getachew A, Byass P, Lindsay SW: Can source reduction of mosquito larval habitat reduce malaria transmission in Tigray, Ethiopia? Trop Med Int Health 2005, 10:1274-1285.

5. Minakawa N, Munga S, Atieli F, Mushinzimana E, Zhou G, Githeko AK, Yan G: Spatial distribution of anopheline larval habitats in Western Kenyan highlands: effects of land cover types and topography. Am J Trop Med Hyg 2005, 73:157-165.

6. Fontaine RE, Najjar AE, Prince JS: The 1958 malaria epidemic in Ethiopia. Am J Trop Med Hyg 1961, 10:795-803.

7. Tesfaye S, Belyhun Y, Teklu T, Mengesha T, Petros B: Malaria prevalence pattern observed in the highland fringe of Butajira. Southern Ethiopia: a longitudinal study from parasitological and entomological survey. Malar J 2011, 10:153.

8. Graves PM, Richards FO, Ngondi J, Emerson PM, Shargie EB, Endeshaw T, Ceccato P, Ejigsemahu Y, Mosher AW, Hailemariam A, Zerihun M, Teferi T, Ayele B, Mesele A, Yohannes G, Tilahun A, Gebre T: Individual, household and environmental risk factors for malaria infection in Amhara, Oromia and SNNP regions of Ethiopia. Trans R Soc Trop Med Hyg 2009, 103:1211-1220.

9. White GB, Tessfaye F, Boreham PFL, Lemma G: Malaria vector capacity of Anopheles arabiensis and An. quadriannulatus in Ethiopia: chromosomal interpretation after 6 years storage of field preparations. Trans $R$ Soc Trop Med Hyg 1980, 74:683-684.

10. Krafsur ES, Armstrong JC: An integrated view of entomological and parasitological observations on falciparum malaria in Gambela, Western Ethiopian Lowlands. Trans R Soc Trop Med Hyg 1978, 72:348-356.

11. Balkew M, Elhassen I, Ibrahim M, Gebre-Michael T, Engers $H$ : Very high DDT-resistant population of Anopheles pharoensis Theobald (Diptera: Culicidae) from Gorgora, northern Ethiopia. Parasite 2006, 13:327-329.

12. Fontenille D, Lochouarn L, Diagne N, Sokhna C, Lemasson JJ, Diatta M, Konate L, Faye F, Rogier C, Trape JF: High annual and seasonal variations in malaria transmission by anophelines and vector species composition in Dielmo, a holoendemic area in Senegal. Am J Trop Med Hyg 1997, 56:247-253.

13. Muriu SM, Muturi EJ, Shililu JI, Mbogo CM, Mwangangi JM, Jacob BG, Irungu LW, Mukabana RW, Githure Jl, Novak RJ: Host choice and multiple blood feeding behaviour of malaria vectors and other anophelines in Mwea rice scheme, Kenya. Malar J 2008, 7:43.

14. Shililu J, Ghebremeskel T, Mengistu S, Fekadu H, Zerom M, Mbogo C, Githure J, Novak R, Brantly E, Beier JC: High seasonal variation in entomologic inoculation rates in Eritrea, a semi-arid region of unstable malaria in Africa. Am J Trop Med Hyg 2003, 69:607-613.

15. Lefevre T, Gouagna LC, Dabire KR, Elguero E, Fontenille D, Renaud F, Costantini $C$, Thomas F: Beyond nature and nurture: phenotypic plasticity in blood-feeding behavior of Anopheles gambiae s.s. when humans are not readily accessible. Am J Trop Med Hyg 2009, 81:1023-1029.

16. Kent RJ, Thuma PE, Mharakurwa S, Norris DE: Seasonality, blood feeding behavior, and transmission of Plasmodium falciparum by Anopheles arabiensis after an extended drought in southern Zambia. Am J Trop Med Hyg 2007, 76:267-274.

17. Shaukat AM, Breman JG, McKenzie FE: Using the entomological inoculation rate to assess the impact of vector control on malaria parasite transmission and elimination. Malar J 2010, 9:122.

18. Okara RM, Sinka ME, Minakawa N, Mbogo CM, Hay SI, Snow RW: Distribution of the main malaria vectors in Kenya. Malar J 2010, 9:69.

19. Beier JC, Asiago CM, Onyango FK, Koros JK: ELISA absorbance cut-off method affects malaria sporozoite rate determination in wild Afrotropical Anopheles. Med Vet Entomol 1988, 2:259-264.

20. Beier JC, Oster CN, Onyango FK, Bales JD, Sherwood JA, Perkins PV, Chumo DK, Koech DV, Whitmire RE, Roberts CR, Diggs CL, Hoffman SL: Plasmodium falciparum incidence relative to entomologic inoculation rates at a site proposed for testing malaria vaccines in western Kenya. Am J Trop Med Hyg 1994, 50:529-536.

21. Beier JC, Killeen GF, Githure Jl: Entomologic inoculation rates and Plasmodium falciparum malaria prevalence in Africa. Am J Trop Med Hyg 1999, 61:109-113. 
22. Fornadel CM, Norris LC, Norris DE: Centers for Disease Control light traps for monitoring Anopheles arabiensis human biting rates in an area with low vector density and high insecticide-treated bed net use. Am J Trop Med Hyg 2010, 83:838-842.

23. WHO: Manual on practical entomology in malaria. Part II. Methods and Techniques. Geneva: Division of Malaria and Other Parasitic Diseases; 1975.

24. Hay SI, Rogers DJ, Toomer JF, Snow RW: Annual Plasmodium falciparum entomological inoculation rates (EIR) across Africa: literature survey, Internet access and review. Trans R Soc Trop Med Hyg 2000, 94:113-127.

25. Davis JR, Hall T, Chee EM, Majala A, Minjas J, Shiff CJ: Comparison of sampling anopheline mosquitoes by light-trap and human-bait collections indoors at Bagamoyo, Tanzania. Med Vet Entomol 1995, 9:249-255.

26. Mboera LE: Sampling techniques for adult Afrotropical malaria vectors and their reliability in the estimation of entomological inoculation rate. Tanzan Health Res Bull 2005, 7:117-124.

27. Norris LC, Fornadel CM, Hung WC, Pineda FJ, Norris DE: Frequency of multiple blood meals taken in a single gonotrophic cycle by Anopheles arabiensis mosquitoes in Macha, Zambia. Am J Trop Med Hyg 2010, 83:33-37.

28. Deressa W, Fantahun M, Ali A: Malaria-related mortality based on verbal autopsy in an area of low endemicity in a predominantly rural population in Ethiopia. Malar J 2007, 6:128.

29. Deressa W, Ali A, Enqusellassie F: Self-treatment of malaria in rural communities, Butajira, southern Ethiopia. Bull World Health Organ 2003, 81:261-268

30. Animut A, Gebre-Michael T, Balkew M, Lindtjorn B: Abundance and dynamics of anopheline larvae in a highland malarious area of southcentral Ethiopia. Parasit Vectors 2012, 5:117.

31. Mboera LE, Kihonda J, Braks MA, Knols BG: Short report: Influence of centers for disease control light trap position, relative to a human-baited bed net, on catches of Anopheles gambiae and Culex quinquefasciatus in Tanzania. Am J Trop Med Hyg 1998, 59:595-596.

32. Gillies MT, Coetzee M: A supplement to the Anophelinae of Africa south of the Sahara (Afrotropical Region). Publ S Afr Inst Med Res 1987, 55:1-143.

33. Scott JA, Brogdon WG, Collins FH: Identification of single specimens of the Anopheles gambiae complex by the polymerase chain reaction. Am J Trop Med Hyg 1993, 49:520-529.

34. Wirtz RA, Sattabongkot J, Hall T, Burkot TR, Rosenberg R: Development and evaluation of an enzyme-linked immunosorbent assay for Plasmodium vivax-VK247 sporozoites. J Med Entomol 1992, 29:854-857.

35. Wirtz R, Avery M, Benedict M: Specific Anopheles Techniques. Plasmodium falciparum Sporozoite. Manassas, USA: ELISA; 2007 [http://www.mr4.org/ portal/3/methodsinAnophelesResearch.pdf] Malaria Research and Reference Reagent Resource Center. MR4

36. WHO: Malaria entomology and vector control: Learner's Guide, Trial Edition HIVI AIDS, Tuberculosis and Malaria, Roll Back Malaria. Geneva: WHO; 2003. http:// whqlibdoc.who.int/hq/2003/WHO/CDS/CPE/SMT/2002.18/Rev.1/Partl.pdf.

37. Ameneshewa B, Service MW: Resting habits of Anopheles arabiensis in the Awash river valley of Ethiopia. Ann Trop Med Parasitol 1996, 90:515-521.

38. Faye O, Konate L, Mouchet J, Fontenille D, Sy N, Hebrard G, Herve JP: Indoor resting by outdoor biting females of Anopheles gambiae complex (Diptera: Culicidae) in the Sahel of northern Senegal. J Med Entomol 1997, 34:285-289.

39. Paaijmans KP, Thomas MB: The influence of mosquito resting behaviour and associated microclimate for malaria risk. Malar J 2011, 10:183.

40. Yohannes M, Boelee E: Early biting rhythm in the Afro-tropical vector of malaria, Anopheles arabiensis, and challenges for its control in Ethiopia. Med Vet Entomol 2012, 26:103-105.

41. Habtewold T, Walker AR, Curtis CF, Osir EO, Thapa N: The feeding behaviour and Plasmodium infection of Anopheles mosquitoes in southern Ethiopia in relation to use of insecticide-treated livestock for malaria control. Trans R Soc Trop Med Hyg 2001, 95:584-586.

42. Tirados I, Costantini C, Gibson G, Torr SJ: Blood-feeding behaviour of the malarial mosquito Anopheles: arabiensis: implications for vector control. Med Vet Entomol 2006, 20:425-437.

43. Hadis M, Lulu M, Makonnen Y, Asfaw T: Host choice by indoor-resting Anopheles arabiensis in Ethiopia. Trans R Soc Trop Med Hyg 1997, 91:376-378.

44. Tirados I, Gibson G, Young S, Torr SJ: Are herders protected by their herds? An experimental analysis of zooprophylaxis against the malaria vector Anopheles arabiensis. Malar J 2011, 10:68.

45. Shililu J, Ghebremeskel T, Mengistu S, Fekadu H, Zerom M, Mbogo C, Githure J, Gu W, Novak R, Beier JC: Distribution of anopheline mosquitoes in Eritrea. Am J Trop Med Hyg 2003, 69:295-302.
46. Taye A, Hadis M, Adugna N, Tilahun D, Wirtz RA: Biting behavior and Plasmodium infection rates of Anopheles arabiensis from Sille, Ethiopia. Acta Trop 2006, 97:50-54

47. Rogerson SJ, Carter R: Severe vivax malaria: newly recognised or rediscovered. PLoS Med 2008, 5:e136.

48. Mahgoub H, Gasim Gl, Musa IR, Adam I: Severe Plasmodium vivax malaria among Sudanese children at New Halfa Hospital, Eastern Sudan. Parasit Vectors 2012, 5:154.

49. Okello PE, Van Bortel W, Byaruhanga AM, Correwyn A, Roelants P, Talisuna A, D'Alessandro $U$, Coosemans M: Variation in malaria transmission intensity in seven sites throughout Uganda. Am J Trop Med Hyg 2006, 75:219-225.

50. Lindsay SW, Martens WJ: Malaria in the African highlands: past, present and future. Bull World Health Organ 1998, 76:33-45.

51. Drakeley C, Schellenberg D, Kihonda J, Sousa CA, Arez AP, Lopes D, Lines J, Mshinda H, Lengeler C, Armstrong Schellenberg J, Tanner M, Alonso P: An estimation of the entomological inoculation rate for Ifakara: a semiurban area in a region of intense malaria transmission in Tanzania. Trop Med Int Health 2003, 8:767-774.

52. Kulkarni MA, Kweka E, Nyale E, Lyatuu E, Mosha FW, Chandramohan D, Rau ME, Drakeley C: Entomological evaluation of malaria vectors at different altitudes in Hai district, northeastern Tanzania. J Med Entomol 2006, 43:580-588.

53. Bodker R, Akida J, Shayo D, Kisinza W, Msangeni HA, Pedersen EM, Lindsay SW: Relationship between altitude and intensity of malaria transmission in the Usambara Mountains, Tanzania. J Med Entomol 2003, 40:706-717.

54. Woyessa A, Deressa W, Ali A, Lindtjorn B: Prevalence of malaria infection in Butajira area, south-central Ethiopia. Malar J 2012, 11:84.

55. Elissa N, Migot-Nabias F, Luty A, Renaut A, Toure F, Vaillant M, Lawoko M, Yangari $\mathrm{P}$, Mayombo J, Lekoulou F, Tshipamba P, Moukangi R, Millet $\mathrm{P}$ Deloron P: Relationship between entomological inoculation rate, Plasmodium falciparum prevalence rate, and incidence of malaria attack in rural Gabon. Acta Trop 2003, 85:355-361.

56. Shililu J, Maier WA, Seitz HM, Orago AS: Seasonal density, sporozoite rates and entomological inoculation rates of Anopheles gambiae and Anopheles funestus in a high-altitude sugarcane growing zone in Western Kenya. Trop Med Int Health 1998, 3:706-710.

57. Himeidan YE, Elzaki MM, Kweka EJ, Ibrahim M, Elhassan IM: Pattern of malaria transmission along the Rahad River basin, Eastern Sudan. Parasit Vectors 2011, 4:109.

58. Mala AO, Irungu LW, Shililu JI, Muturi EJ, Mbogo CM, Njagi JK, Mukabana WR, Githure Jl: Plasmodium falciparum transmission and aridity: a Kenyan experience from the dry lands of Baringo and its implications for Anopheles arabiensis control. Malar J 2011, 10:121.

59. Teklehaimanot HD, Lipsitch M, Teklehaimanot A, Schwartz J: Weather-based prediction of Plasmodium falciparum malaria in epidemic-prone regions of Ethiopia I. Patterns of lagged weather effects reflect biological mechanisms. Malar J 2004, 3:41.

60. Mouchet J, Ircoulon J, Laventure S, Faye O, Onapa AW, Carnevale P, Julvez J, Ontenille D: Evolution of malaria in africa for the past 40 years: impact of climatic and human factors. J Am Mosq Control Assoc 1998, 14:121-130.

\section{doi:10.1186/1475-2875-12-76}

Cite this article as: Animut et al:: Blood meal sources and entomological inoculation rates of anophelines along a highland altitudinal transect in south-central Ethiopia. Malaria Journal 2013 12:76.

\section{Submit your next manuscript to BioMed Central and take full advantage of:}

- Convenient online submission

- Thorough peer review

- No space constraints or color figure charges

- Immediate publication on acceptance

- Inclusion in PubMed, CAS, Scopus and Google Scholar

- Research which is freely available for redistribution 